D. Francisco Fernández

\title{
SOBRE LA INTERPRETACIÓN DEL CAMBIO LINGÜÍSTICO
}

UNIVERSIDAD DE VALENCIA 
El problema del ser y del devenir / de la continuidad-en-el-cambio/ de la evolución de las especies o de las lenguas / ... ha sido objeto de reflexión por parte de filósofos, educadores, biólogos, lingüistas, etc. ... desde tiempo inmemorial.

En lo que respecta a la lingüística, la cuestión se ha complicado con la aparición de numerosos estudios en torno a una serie de cambios que se manifiestan en las lenguas y que no parecen ser el resultado de las motivaciones y/o recursos internos de ellas mismas (sino del contacto con otras lenguas), así como en torno al surgimiento de lenguas completamente nuevas (los pidgins y los idiomas criollos) que son igualmente el resultado del contacto entre lenguas.

Los estudios sistemáticos sobre los pidgins y los idiomas criollos comenzaron, como es sabido, ya hace más de un siglo (con las valiosas aportaciones de Hugo Schuhardt). Sin embargo, para la mayoría de los lingüistas, anclados todavía en los principios del comparativismo lingüístico, estas lenguas se vieron pronto rechazadas y relegadas a simples excepciones que no ofrecían el menor interés para la teoría lingüística.

Y, en opinión de L. Todd (1990: 1), dichas lenguas siguen todavía calificándose como "inferior, haphazard, broken, bastardized versions of older, longer established languages".

Pero afirmaciones de esta índole no dejan de llamar la atención, puesto que el número de publicaciones en torno al contacto lingüístico en general y las consecuencias del mismo - la transferencia de elementos de una lengua a otra y los cambios de todo tipo que resultan del contacto entre lenguasha aumentado considerablemente en los últimos años; y también porque creo que las actitudes de menosprecio hacia esas lenguas han desaparecido 
[debido, entre otras cosas, al hecho de que los más de 200 pidgins e idiomas criollos ya identificados - aunque se encuentren en su mayoría en zonas restringidas y aunque no representan un alto porcentaje entre el total de los hablantes del mundo contemporáneo- resultan ciertamente algo más que un par de meras excepciones sin interés alguno para el lingüista].

De hecho el convencimiento de Schuhardt [de que todas las lenguas son una mezcla de múltiples elementos de varias otras lenguas] parece haberse generalizado ahora y traducido en el rechazo (o, al menos, "cuestionamiento") de la representación tradicional de las relaciones lingüísticas (y de la historia de las lenguas) en términos de árboles genealógicos (Mühlhäusler 1980: 34), y en la consiguiente aceptación general de las interferencias foráneas que han tenido, y siguen teniendo, lugar en la historia de la gran mayoría de las lenguas del mundo contemporáneo.

El estudio del contacto entre lenguas, como área del saber con identidad propia, me parece pues definitivamente establecido y cada día más arraigado y generalizado, aunque todavía, y quizá demasiado a menudo, muy controvertido.

Identificar con exactitud dónde está la clave / el punto neurálgico que origina y perpetúa la controversia no resulta nada fácil. Me parece, sin embargo, que un modelo teórico que abordara la cuestión en toda su complejidad sería de grandísima utilidad y contribuiría, desde luego, a una mejor comprensión de la evolución de las lenguas. Se me ocurre que dicho modelo teórico podría plantearse/formularse, al menos de forma provisional, en términos de alguna de las clásicas dicotomías saussureanas: la perspectiva diacrónica frente a la sincrónica, por ejemplo. O bien en términos de otras dicotomías como podrían ser: el cambio linguiístico de motivación interna frente al cambio lingüístico de motivación externa; y todavía más adecuadamente, quizá, en términos del concepto actual (post-darwiniano) del término evolución (tan frecuentemente invocado y conjurado por lingüistas y filólogos) frente al concepto decimonónico (pre-darwiniano) de dicho término.

Aunque pueda sonar al típico compromiso del super-prudente (o del perpetuo indeciso), estoy convencido de que -como ocurre a menudo- la verdad (=la "virtud") puede que esté en algún "punto medio" entre los dos polos opuestos de alguna de las dicotomías mencionadas (o de otras que pudieran mencionarse en términos más adecuados). Trataré de comprometerme, sin embargo, en lo que pueda; y espero que acertadamente.

Me parece, en primer lugar, que cierto número de publicaciones - basándose en la similitud de algunos cambios lingüísticos que son característicos de las lenguas en contacto- parecen equiparar, al menos implícita- 
mente, procesos muy diferentes. Así el proceso de extinción o muerte de una lengua, por ejemplo, presenta semejanzas evidentes con los procesos de pidginización y criollización (que, a su vez, contribuyen al nacimiento de una nueva lengua): todos estos procesos suponen el contacto linguístico, están en gran medida motivados por factores sociales, pueden catalogarse como sub-conjuntos del cambio linguíístico; y todos parecen tener implicaciones importantes para la teoría lingüística en general, así como para la adquisición de la lengua y el cambio linguístico en particular.

Pero se dan también diferencias manifiestas e importantes entre ellos. Las más manifiestas entre la pidginización y la extinción/muerte de una lengua, por ejemplo, tienen que ver con las situaciones socio-culturales en las que dichos procesos tienen lugar; entre otras, las siguientes me parecen importantes: el proceso de pidginización es el primer paso en el desarrollo de una lengua nueva, mientras que el de la extinción o muerte es ciertamente el último; la pidginización comienza a darse en situaciones formales, entre extraños y con una finalidad frecuentemente relacionada con la actividad comercial, mientras que las lenguas en proceso de extinción/muerte suelen hablarse en situaciones no formales, entre individuos que comparten lazos personales íntimos; la extinción o muerte de una lengua se da en situaciones de bilingüismo, mientras que la pidginización se da en comunidades multilingüies (por lo menos trilingües); las lenguas en proceso de extinción/ muerte tienen hablantes nativos (aunque totalmente bilinguies), mientras que los pidgins no son el idioma nativo de nadie; etc.

A la vista de tantas discrepancias, las similitudes entre la pidginización y la extinción/muerte de una lengua parecen reducirse a la simple ocurrencia de algunos cambios linguiísticos que son característicos de las lenguas en contacto. En otras palabras: dada la multitud de fenómenos que pueden caracterizarse como propiciados por el contacto entre lenguas, no parece que sea éste un criterio válido y suficientemente sólido en el que podamos apoyarnos para identificar y caracterizar ambos procesos. De modo que, si equiparamos la pidginización con la extinción/muerte de una lengua [y quizá también con varios otros procesos resultantes del contacto entre lenguas], estamos sencillamente creando una categoría tan amplia y genérica que caben en ella multitud de cambios que tienen en común el ser consecuencia del contacto entre lenguas, pero que son muy diferentes, si consideramos sus contextos individuales. Y tales categorías pierden pronto su significado, a menos que las encuadremos en un modelo teórico más general que las englobe y dé sentido.

Los intentos de hacerlo han cristalizado en propuestas de nuevas tipologías de las lenguas en las que se suele distinguir entre: 
- Lenguas que, en su evolución, siguen o encajan bien en el modelo genético común [el de los árboles genealógicos tradicionales], y

- Lenguas mixtas que, de resultas de las interferencias foráneas tan acusadas, han seguido (en su evolución) una vía no genética. (Thomson \& Kaufman 1988),

precisando que la evolución de las primeras se estudia y analiza mejor desde la perspectiva diacrónica [puesto que presentan series de cambios de motivación básicamente externa]; mientras que las segundas se estudian y analizan mejor desde la perspectiva sincrónica [ya que la abrumadora mayoría de cambios que se dan en ellas son el resultado de motivaciones externas a dicha lengua].

$\mathrm{Y}$, al tratar de analizar y estudiar las así llamadas lenguas mixtas, se ha apuntado y subrayado la importancia de los préstamos en la aparición de los pidgins, la de las interferencias subestráticas en el desarrollo de los idiomas criollos y la de las interferencias superestráticas en los procesos de descriollización de lenguas, así como de la extinción/muerte de una lengua dada.

Aunque sin intentar discutir aquí y ahora etiquetas de este tenor, me parece que la cuestión está en que - si entendemos el préstamo lingüístico como toda incorporación (por parte de los hablantes nativos) de elementos foráneos en su propia lengua nativa; y las interferencias subestráticas y superestráticas, en la línea de las teorías de difusión y variación linguísticasentonces resulta que los préstamos, al igual que las interferencias subestráticas y superestráticas, están también presentes en la evolución de todas y cada una de las lenguas, como demuestran los trabajos recientes sobre dialectologías y difusión lingüística o sobre los procesos de descriollización y recriollización.

Sencillamente me parece que propuestas de este tipo no resultan adecuadas, puesto que todas las lenguas del mundo puede decirse que son realmente lenguas en contacto y que la diferencia entre las mismas es más cuestión de cantidad que de cualidad; por lo que podríamos hablar de

- Lenguas con un alto grado de contacto, en las que se puede apreciar un gran número de cambios "no-naturales": los pidgins y los estadios primeros de criollización; y

- Lenguas con un bajo grado de contacto, en las que la mayoría de los cambios observables son "naturales": los idiomas criollos, las lenguas descriollizadas, los standards nacionales, ... (Trudgil 1984).

Lo cual hasta podría entenderse como la formulación de otra posible dicotomía del tipo ya mencionado arriba [con tal de no conectar "naturales" con similitudes tipológicas, teleologías funcionales o intencionales, etc. y 
"no-naturales" como todo lo opuesto]. De hecho, me parece que la pidginización, al igual que la criollización, deberian entenderse (como ya lo expresaba Traugott 1977: 74) no como tipológicamente diferentes de otros procesos del cambio lingüístico, sino como casos extremos de la "hibridación" que está teniendo lugar en las lenguas en todo momento; y, en consecuencia, que tanto la pidginización como la criollización pueden haber formado parte de lenguas que ahora no se clasificarían en modo alguno como pidgins y/o idiomas criollos. Y por ello las posiciones que, de alguna manera, plantean la existencia de períodos de pidginización o de criollización del inglés durante el inglés medio o después de la "escandinavización" respectivamente -0 situaciones similares en el español, francés, italiano, etc. ... en el período que va desde el latín vulgar hasta la aparición de los primeros textos romance - no me parecen tan descabelladas y hasta ridículas como Thomason \& Kaufmann (1991), por ejemplo, pretenden probar.

Algunas otras propuestas, como por ejemplo

- De serializaciones en una escala de evolución progresiva, tales como: de la jerga no sistemática $\longrightarrow$ al pidgin estabilizado $\longrightarrow$ al idioma criollo $\longrightarrow$ a la descriollización $\longrightarrow$ al standard nacional

- De paralelismos (con evaluaciones implícitas) del tipo: pidgin = aprendizaje de la segunda lengua [con input restringido]; criollización $=\mathrm{el}$ habla del extranjero y/o el aprendizaje de la primera lengua por parte de los primeros descendientes de extranjeros [con input también restringido]; descriollización $=$ aprendizaje de la lengua materna; ...

- Etc.

pueden resultar útiles y hasta esclarecedoras en algunos aspectos; pero dudo que puedan ayudarnos mucho a comprender la cuestión del cambio lingüístico (y consiguiente evolución de la lengua) en toda su complejidad.

Me parece que una visión de la evolución lingüística en el sentido actual (post-darwiniano) del término evolución, frente a la posición lingüística decimonónica (con un concepto pre-darwiniano del término evolución) podría contribuir a aclarar la cuestión y ayudarnos a perfilar un modelo teórico que contemple el cambio y evolución lingüísticos en general.

\section{El concepto pre-darwiniano de evolución}

Aunque Saussure, por ejemplo, parece haberse opuesto siempre a todo tipo de metáforas y analogías tomadas de otros campos del saber —más recientemente, Wells (1987: 42) las califica de "recurso de amateurs" y en McMahon (1994: 314) leemos que "evolution, in particular, has become a dirty word in modern linguistic theory"-, los filósofos han recurrido fre- 
cuentemente a modelos y conceptos biológicos; y recientemente parece apreciarse un resurgir de las metáforas biológicas, especialmente en la lingüística histórica y en el campo de las lenguas en contacto. Acabo de mencionar, por ejemplo, los conceptos de aparición/nacimiento y de extinción/muerte de una lengua.

Pero - al leer muchas de esas publicaciones en torno a la historia de varias de las lenguas concretas y su interpretación de la evolución de las mismas- uno se pregunta si sus autores no siguen todavía anclados en un concepto trasnochado de la metáfora biológica.

Los lingüistas y filólogos del s.XIX utilizaron ciertamente algunos términos y conceptos biológicos; pero manejaban el concepto de evolución en un sentido pre-darwiniano (incluso Schleicher, a quien se ha calificado a menudo como darwiniano).

Adoptaron, en efecto, la idea del transformismo [rechazando todo "creacionismo", así como la doctrina del "fijismo" de las especies de Linneo]; y adoptaron también la idea de la herencia genética formulada por Lamarck, quien (a comienzos del s.XIX) sugería ya la distinción entre el material genético [ahora conocido como DNA] y el somático o corporal.

Pero no captaron [y, en consecuencia, tampoco pudieron aceptar] la noción esencialmente darwiniana de que la evolución tiene lugar gracias a la mutación, la variación y la selección natural. A grandes rasgos, y sintetizando al máximo, digamos que las mutaciones genéticas son arbitrarias y surgen espontáneamente en los organismos originando alteraciones o cambios mínimos y sin importancia [tales como patas más largas, diferente matiz en la pigmentación, etc. ...]. No en todos los organismos aparece la misma mutación; y precisamente por ello nos encontramos con cierta variación en las especies [ya que en algunos organismos aparecen los rasgos de la mutación, mientras que en otros no]. Las variantes que se han desarrollado pueden sencillamente coexitir las unas con las otras; pero puede también darse una selección natural que favorezca cierta(s) variedad(es) que se haya(n) adaptado mejor a su entorno.

Puesto que la mutación es arbitraria, los cambios no siempre resultan positivos y beneficiosos para los organismos y, en consecuencia, es imposible considerar la selección natural como una especie de diseño maravilloso y providencial que manipule las especies hacia una mejora y perfeccionamiento siempre crecientes. De hecho, puede igualmente considerarse como un proceso negativo: (1) comienzan a surgir las variedades; (2) aquellas que no se adaptan bien al entorno, decaen y se extinguen; y (3) únicamente las supervivientes continúan desarrollándose y evolucionando.

Es decir, que - mientras que la teoría evolucionista excluye toda noción 
de progreso y perfeccionamiento- los lingüistas del s. XIX insistían en la idea del ciclo vital: los organismos [y, por consiguiente las lenguas] se consideraban como entidades que nacían, experimentaban un crecimiento progresivo (desde un estadio primitivo hasta su máximo desarrollo), luego decaían también progresivamente y finalmente morían.

$\mathrm{El}$ árbol de las lenguas indoeuropeas de Schleicher ha servido obviamente de modelo a otros árboles genealógicos; pero está claramente influenciado por la taxonomía sincrónica linneana. Schleicher, en efecto, equiparaba las familias linguísticas con los géneros, las lenguas individuales [o nacionales] con las especies, los dialectos con las razas y los idiolectos con los organismos concretos e individuales (Koerner 1983: 31-32). Y según él — siguiendo más a Hegel que a Darwin- la vida de las lenguas presenta tres períodos claramente observables: (1) crecimiento o avance, (2) un breve período glorioso de perfección evolutiva, y (3) un proceso regresivo irrevocable.

En realidad la exposición que Schleicher hace sobre el origen de las lenguas es más bien pobre. Da por supuesto que, en un principio, se dieron muchas lenguas primitivas que constaban de elementos radicales sencillos e invariables; estos elementos linguísticos antiguos eran sólo sonidos que designaban objetos y conceptos; no existían los tipos de palabras, ni las diferentes declinaciones, conjunciones, etc. $y$, en consecuencia, no se expresaban las relaciones (Koerner 1983: 80). Muchas de esas lenguas primitivas se extinguieron; pero las que sobrevivieron comenzaron un largo ascenso evolutivo hacia la perfección.

Llegados a este punto, la cuestión obvia es cómo se mide el progreso en términos lingüísticos. Y la respuesta habitual del lingüista del siglo pasado sería que "a mayor complejidad (sobre todo morfológica), mayor desarrollo y más alto nivel de perfección lingüística".

De modo que la clasificación de las lenguas en aislantes, aglutinantes y flexivas no se interpretaba como una trilogía estática, sino como una escala evolutiva que ascendía desde un período en el que predominaban los rasgos típicamente aislantes o analíticos, hasta otro que se caracterizaba por rasgos marcadamente sintéticos [primero aglutinantes y luego flexivos]. Y, una vez que la lengua alcanzaba este nivel de desarrollo, la evolución concluía, iniciándose a la vez un proceso regresivo y decadente [desde las estructuras sintéticas hacia las analíticas]'.

1. Es decir, que las lenguas de un sistema flexivo muy complejo (como el griego o el latín) representarían el nivel más elevado de evolución linguiística. 
Muy pronto [todavía enmarcadas en el paradigma de la lingüística tradicional] comenzaron a oirse las críticas a esta hipótesis. Una de las primeras y más conocidas reacciones fue la de $\mathrm{O}$. Jespersen, quien proponía justamente la hipótesis contraria: las lenguas europeas contemporáneas [que han perdido la mayoría de sus inflexiones] son "mejores" (=más perfectas) que sus predecesoras [de un marcado carácter flexivo], puesto que permiten un máximo de eficiencia comunicativa con un mínimo esfuerzo lingüístico. Jespersen mantiene que una característica general, observable en todas las lenguas, es la evolución y desarrollo progresivos desde las estructuras sintéticas hacia las analíticas. Pero Jespersen se basa únicamente (o al menos principalmente) en las lenguas indoeuropeas; sería, por consiguiente, muy difícil predecir lo que hubiera afirmado de haber tomado en consideración también el caso del Tok Pisin, por ejemplo².

Lo cierto es que, tanto en la hipótesis de Schleicher como en la de Jespersen, pueden observarse excepciones manifiestas; y es que las lenguas parecen cambiar tanto desde lo analítico hacia lo sintético como viceversa, o pueden incluso evolucionar en un cierto sentido en algunas áreas o categorías gramaticales concretas y en el sentido opuesto en otras.

El convencimiento de Schleicher de que las lenguas han llegado a un punto desde el que se inicia su decadencia se apoya en la posición tradicional que considera el cambio como un proceso esencialmente retrógrado y degenerativo que debería, en lo posible, detenerse [como S. Johnson apuntara ya en el prólogo a su Diccionario de la lengua inglesa] y es componente esencial de la nostalgia humana, de la creencia en una edad de oro que se sitúa siempre más allá de la memoria de los hablantes contemporáneos y que se refleja en el convencimiento de que las lenguas en su estado actual, al igual que las manifestaciones de las mismas [en especial la literatura y todo género de expresión artística) están, en alguna medida, envilecidas o empobrecidas, si se las compara con ese estadio o período glorioso.

Esta concepción pre-darwiniana de la evolución ha sido ampliamente criticada y se ha ido rechazando por la mayoría de los linguiistas, a medida que el prescriptivismo decimonónico iba dejando paso al descriptivismo del s.XX [y al convencimiento de que todas las lenguas deben considerarse como iguales]. Y la posición actual ante la cuestión [al menos la de la lingüística histórica] es sencillamente la de que todas las lenguas cambian; podemos tratar de describir y explicar los procesos del cambio; pero no

2. El tok pisin, como es sabido, es un pidgin de base sólo parcialmente indoeuropea que -en su progresivo proceso de gramaticalización - parece avanzar precisamente desde el ideal analítico de Jespersen hacia unas estructuras sintéticas. 
existe nada que justifique la visión del cambio como un progreso o retroceso creciente. Las lenguas modernas, las ya extinguidas, así como las reconstruidas [mediante procesos de descriollización, por ejemplo] se sitúan a un nivel de complejidad estructural y de eficiencia comunicativa aproximadamente idénticos; y en modo alguno puede afirmarse que ciertas lenguas [o períodos en la historia de las mismas] sean mejores que otras [u otros].

$Y$, por otro lado, parece claro que las lenguas se extinguen (=mueren) debido a factores socio-políticos y no a males o vicios inherentes a las mismas [como puede apreciarse en los casos del húngaro en Austria (Gal 1979) o del gaélico en Irlanda (Hindley 1990)].

\section{El modelo teleológico}

Una alternativa a este concepto pre-darwiniano de evolución ha sido el modelo teleológico que considera el cambio linguístico como acumulativo y encaminado hacia un fin preestablecido. Así, si en una lengua dada nos encontráramos con las reglas fonológicas siguientes

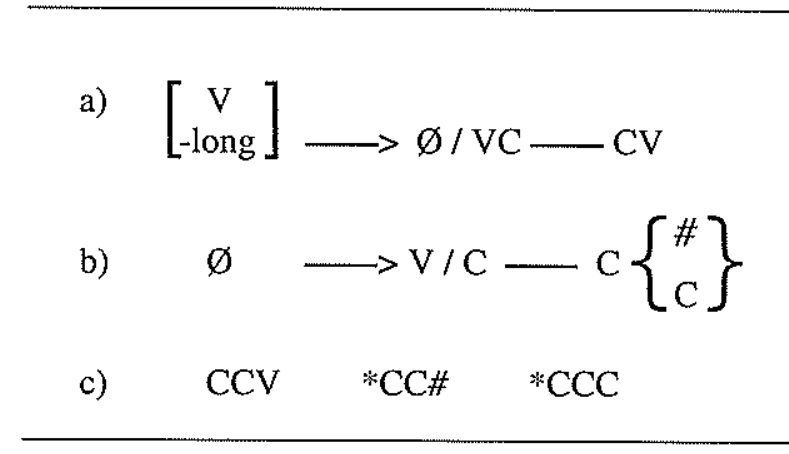

entenderíamos que

- La regla a) se aplica sólo en el entorno $\mathrm{VC}-\mathrm{CV}$, en el que origina la secuencia correcta CCV. Si se aplicara en cualquier otro contexto [como por ejemplo $\mathrm{C}-\mathrm{C \#}$ o bien $\mathrm{CC}-\mathrm{C}$ ] originaría las secuencias incorrectas $* \mathrm{CC} \#$ o bien ${ }^{*} \mathrm{CCC}$. La regla, por consiguiente, se aplica sólo cuando no se opone a ninguno de los principios fonotácticos de dicha lengua.

- La regla b), por su parte, inserta una vocal precisamente en aquellas secuencias en las que, de no hacerlo, se originarían (en la estructura de superficie) las secuencias incorrectas $* \mathrm{CC} \#$ o bien $* \mathrm{CCC}$. 
Las dos reglas parecen deber su forma a la misma restricción fonética, en la estructura de superficie, y parecen también contribuir conjuntamente [o "conspirar"] para que puedan darse determinadas secuencias fónicas $y / 0$ para impedir que algunas otras puedan originarse en la estructura de superficie de la lengua en cuestión. Tales reglas [que se aúnan, se relacionan entre sí, o conspiran en orden a lograr determinados fines] suponen claramente una motivación común y son, pues, teleológicas. ${ }^{3}$ El objetivo [o resultado final] suele determinar la forma de las reglas; y no es absolutamente necesario que dicho objetivo suponga una mejora o un progreso en la evolución de la lengua. [De hecho, los cambios teleológicos pueden tener resultados positivos, neutros o negativos para (la estructura de) la lengua.

Este recurso a unas causas que presuponen una determinada finalidad ha introducido en la lingüística histórica nuevas posibilidades de explicación y justificación del cambio linguístico. En general estamos acostumbrados y solemos recurrir a explicaciones de tipo causal, según las cuales $\mathrm{Y}$ [=el "efecto"] se ha producido debido a X [=la "causa"]. Desde la perspectiva teleológica, diríamos que $\mathrm{X}$ ha tenido lugar $[=$ ha actuado] para que $\mathrm{Y}$ fuera como ha resultado ser (y es ahora).

En lo que respecta a la evolución fonológica, muchas de las explicaciones tradicionales de los varios cambios fonológicos son, desde luego, susceptibles de una reinterpretación teleológica. Así, por ejemplo, si en una lengua aparecen (en un período A) grupos consonánticos del tipo [mb], [md], [mk], [nb], [nd], [nk], [N b], [Ñd], [N $\mathrm{N}], \ldots$ y en un período $\mathrm{B}$ (posterior) sólo grupos de consonantes homorgánicas [mb], [nd], [Ñk], podemos tratar de explicarlo de dos formas:

1. En el modelo tradicional -y siempre en el marco de la lógica de la relación "causa-efecto"- diríamos que, en esa lengua, se han desarrollado grupos de consonantes homorgánicas, debido a la asimilación fonética.

2. En el modelo teleológico, sin embargo, los grupos de consonantes han resultado homorgánicas para que ahora se dé el mínimo esfuerzo articulatorio en su pronunciación.

El estudio sobre la regla de longitud vocálica en el escocés (de Roger

3. Se trata de reglas fonológicas del Yawelmani (tomadas de Kenstowicz \& Kisseberth 1979). Y podría decirse a) y b) no están relacionadas entre sí, puesto que tienen efectos contrarios en la estructura de superficie [una elimina vocales, mientras que la otra las genera]; pero, si se consideran las combinaciones de consonantes y vocales que son correctas en el Yawelmani y las que no lo son -que se especifican en la regla c)—, sin embargo, la conexión entre las mismas resulta evidente. 
Lass) podría ser un buen ejemplo de este tipo de reinterpretaciones; y lo mismo podría decirse de algunos estudios sobre ciertos casos de homonimia o de ambigüedades léxicas no muy cómodas para el hablante que hubieran podido producirse en la evolución fonológica regular de las lenguas [como por ejemplo, la del término del inglés antiguo sçyttan, que ha dado lugar al inglés moderno shut; de haberse producido la evolución regular, habría resultado shit].

R. Lass concluye enfatizando el hecho de que tenemos un conjunto de cambios fonéticos, aparentemente no relacionados entre sí, que han ido teniendo lugar a lo largo de la historia de una lengua; y que, tras dichos cambios (o como consecuencia de ellos), la lengua presenta ahora unos rasgos tipológicos distintos. La teleología - según él- trataría de mostrar cómo esos cambios se produjeron en una dirección predeterminada que debía resultar en el estado actual de la lengua.Y la realidad del estado actual es suficiente explicación a ese conjunto de cambios fonéticos, que pueden, por consiguiente, considerarse como parte de una conspiración histórica encaminada a producir la tipología que presenta ahora la lengua [u otra tipología futura, hacia la cual ésta es tan sólo una etapa transitoria].

A lo largo de la historia de las ideas y de la lingüística se han ido sucediendo, como en un movimiento pendular, los razonamientos a favor y en contra de la teleología:

a) Para Aristóteles la idea de un universo no teleológico era inconcebible.

b) Para Bloomfield, por el contrario, la teleología imposibilita cualquier tipo de investigación, puesto que proporciona respuestas prefabricadas a cualquier cuestión que se nos pueda plantear.

c) En la fonología generativa apenas se presta atención a la teleología, aunque la noción del máximo de sencillez o economía, que busca en todas sus formulaciones, podría muy bien calificarse de teleológica.

d) R. Jakobson, por su parte, sostiene que cualquier cambio en el sistema fonológico es necesariamente intencional. ${ }^{4}$

e) En el darwinismo, la teleología es anatema; o, por lo menos, un recurso pseudo-explicativo de corte romántico, apocado y obscurantista (Lass 1980).

Y, en efecto, la gran objeción a la teleología tiene que ver con lo problemático que resulta apoyarse en un estado futuro para explicar acontecimientos

4. De esta posición de Jakobson surgiría el concepto praguiano del cambio terapéutico, según el cual todo cambio rompe el equilibrio del sistema; y el equilibrio sólo puede restablecerse gracias a cambios ulteriores. 
pasados [o que están teniendo lugar], sin olvidar desde luego la distinción no siempre clara entre teleología funcional e intencional, esta última [la teleología intencional] todavía más problemática que la anterior.

Vincent (1978) mantiene que la lengua quizá no sea teleológica, pero que los hablantes ciertamente lo son; y es que las decisiones conscientes (e intencionadas) de los hablantes parecen absolutamente claras al tratarse del origen y fijación de muchos de los tabúes y eufemismos, así como de ciertos casos de prescriptivismo [por ejemplo, "no se dice me se cayó, sino se me cayó"]. Pero se trata de casos que suelen afectar sólo al vocabulario o a algún rasgo estructural específico, y no al sistema lingüístico en cuanto tal; y suelen tener como objetivo no el comienzo u origen de algún cambio sino el final o la eliminación de algo (incorrecto) que ha surgido ya, y que se está dando ahora, entre ciertos usuarios de la lengua. Desde luego ningún hablante ha permanecido durante todo el milenio que han tardado en cristalizar las leyes teleológicas de la longitud vocálica del inglés, por ejemplo, para garantizar la intencionalidad de las mismas.

No resulta nada fácil demostrar que las explicaciones teleológicas sean falsas; pero tampoco lo es demostrar que sean ciertas; se apoyan en algunas "meta-reglas" que controlan el que los cambios particulares y concretos se produzcan en un sentido y se ordenen a la consecución de un fin preestablecidos, y en definitiva en la fe, en la idea de la predestinación y de alguien omnisciente que nos ha guiado [y guiará] en todo momento. Por lo que el concepto del término evolución no se corresponde en modo alguno con el del darwinismo, ya que el cambio así entendido no puede decirse que sea aleatorio.

\section{La teoría evolucionista de Darwin y la evolución linguística}

Las dificultades que presenta el concepto tradicional de evolución, así como lo insatisfactorio de las explicaciones teleológicas, podrían quizá justificar la conocida observación de Stevick (1963: 159): "bad luck with biological models has left historical linguistics with such a heritage of confusion and specious explanations as to condition linguists to reject or ignore all putative parallels between languages and living organisms".

Pero por lo general esas confusiones se han dado, no debido a inadecuaciones inherentes a las metáforas biológicas, sino porque los lingüistas no siempre han comprendido bien los conceptos que barajaban; o porque han tomado las comparaciones muy al pie de la letra, entendiendo las lenguas como organismos (humanos) y atribuyéndoles características típicas de tales organismos [=ciclos vitales, racionalidad, consciencia, etc. ...]. 
De hecho, a mí me parece que existen claras analogías entre la teoría evolucionista de Darwin y la evolución lingưuística; y que las similitudes entre ambas podrían ayudarnos al momento de estructurar un modelo teórico que pueda interpretar congruentemente el cambio lingüístico. El énfasis del siglo pasado en la corrupción y decadencia, y el predominio del prescriptivismo en los estudios lingüísticos no permitían tales analogías; los neogramáticos —que establecieron ya la regularidad del cambio linguístico, introduciendo así cierto orden en la historia de las lenguas- tampoco prestaron la atención debida a la variación lingüística (las variantes dialectales, los idiolectos, ...). En la lingüística histórica actual, sin embargo, el descriptivismo ha desplazado al prescriptivismo; se reconoce la importancia de los factores sociales en el cambio [que no se contempla ya como algo puramente mecánico]; y se considera a (cada uno de) los hablantes como causante(s) de la variación y, en consecuencia, generador(es) del cambio linguístico. Esta conexión entre variación y cambio permite la utilización de la teoría evolutiva de Darwin en la lingüística, al igual que se hace en la biología.

Las lenguas y las especies biológicas son ciertamente dos sistemas que están cambiando continuamente y mantienen, sin embargo, su identidad en [y a través de] el tiempo. Esa noción de continuidad-en-el-cambio se ha formulado en la doctrina del transformismo de las especies y de las lenguas, y se ha traducido gráficamente en los árboles taxonómicos tanto de las lenguas como de las especies biológicas; árboles que no tienen por qué rechazarse ahora, aunque sí habrá que liberarlos de las ideas decimonónicas de progreso constante hacia la perfección y ulterior regreso (en decadencia continuada que conduciría hacia una degeneración final).

Tanto las lenguas como las poblaciones biológicas poseen en común otras dos características: las estructuras pueden transmitirse de generación en generación y las variedades que se aíslan las unas de las otras tienden a desarrollarse de modo diferente. Aunque todavía comprendamos muy imperfectamente los mecanismos de transmisión de la lengua [no sabemos con precisión, por ejemplo, hasta qué punto son genéticos y hasta qué punto lo son medioambientales], sí que el aislamiento de las variedades o diferencias linguiísticas [debido a la distancia geográfica y/o a las fronteras socio-políticas] conduce también al desarrollo de "variantes" que pueden eventualmente resultar en lenguas distintas [al igual que ocurre con las especies biológicas aisladas geográficamente].

No estoy equiparando las lenguas con las especies biológicas, puesto que existen también claras diferencias entre ambas. La más notoria es, quizá, el que las lenguas no presentan distinción entre uso y transmisión [como 
ocurre en la biología]. De hecho, una lengua puede adquirir todo tipo de material de cualquier otra [aún sin estar genética o tipológicamente emparentada con ella]; y los cambios que se dan en la vida de un hablante pueden transmitirse fácilmente a sus descendientes; lo cual no es válido en biología, uno de cuyos axiomas es el de que "Ios rasgos físicos adquiridos no pueden transmitirse genéticamente" (Gilman 1987:4) ${ }^{5}$. De donde se sigue que las barreras entre ramas no pueden traspasarse en los árboles genealógicos de las especies biológicas; mientras que, en los árboles lingüísticos, sí que pueden traspasarse, debido a cambios sociales y políticos, a los préstamos y otros fenómenos de contacto.

Si nos fijamos de nuevo en las semejanzas advertiremos que ambas disciplinas distinguen entre variación y cambio. La variación es, en realidad, el conjunto de diferencias en sí mismas, sin relación alguna con el tiempo; mientras que las diferencias que se van dando en el eje de la sucesión temporal, constituyen el cambio. Y ambas se consideran como independientes la una del otro (Stevick 1963: 164). Esta conexión entre variación y cambio es típica de muchos de los trabajos en lingüística histórica durante las últimas décadas, sobre todo los de Labov y algunos otros que han utilizado métodos socio-linguiísticos similares.

La ocurrencia del cambio, por otro lado, es imposible de predecir tanto en la lingüística como en la biología, ya que el cambio resulta de mutaciones aleatorias y casuales. Sólo que la biología siempre ha prestado mayor atención a la variación que la lingüística; de modo que cuando los neogramáticos estaban todavía intentando establecer la regularidad del cambio lingüístico, los biólogos no sólo lo habían establecido, sino que estaban formulando ya algunas de las condiciones de la regularidad en el cambio evolutivo y en la variación aleatoria. (Stevick 1963: 165)

Esta adaptación y aplicación del modelo biológico puede plantear problemas para la lingüística histórica. Si aceptamos que la variación surge espontáneamente y al azar, ¿cómo puede resultar que el cambio lingüístico sea básicamente regular y que períodos sucesivos de las lenguas resulten ordenados y sistemáticos? La aparente paradoja podría explicarse tomando una noción más de la biología, puesto que "el orden resulta de combinar el azar y la selección" (Stevick 1963: 165). Este axioma podría ayudarnos a solucionar el problema de la direccionalidad intencional, para la que se habían propuesto explicaciones teleológicas [sobre todo en fonología, como

5. Si mi mujer y yo (ambos de raza blanca) nos ponemos morenos durante el verano, por ejemplo, y luego tenemos un hijo/-a, está claro que el niño/-a no nacerá por ello moreno. 
ya he apuntado; pero también en otras áreas, principalmente en situaciones de lenguas en contacto, como las que se dan en la formación de los pidgins o en los procesos de criollización y descriollización].

La direccionalidad intencional se acepta en la teoría evolucionista actual como resultante de la variación aleatoria y de la selección natural. Los hablantes originan cambios en las lenguas por sus actos de habla. Algunos hablantes, por ejemplo, pueden seleccionar (consciente o inconscientemente) una variante concreta para manifestar su pertenencia a un grupo social determinado. Pero tales actos [con una finalidad así de preconcebida] apenas sobrepasan la situación inmediata, aunque sí puedan contribuir, de forma no intencional, al cambio lingüístico gradual (Nerlich 1989: 105).

Tendríamos que plantearnos varias otras cuestiones si es que hemos de hacer un uso adecuado de la metáfora evolutiva en la lingüística histórica. No sabemos, por ejemplo, sobre qué unidades puede actuar la selección natural en la historia de la lengua [si es sobre las palabras, sobre las reglas o las estructuras, sobre los hablantes o sobre las lenguas en sí mismas], ni tampoco en qué orden actúa (cuando lo hace). No sabemos si la evolución lingüística se rige sólo por tendencias generales y universales o si éstas pueden ser anuladas por factores lingüísticos específicos. Tampoco se ha formulado todavía bajo qué condiciones puedan "conspirar" la variación y la selección en orden a originar y obtener la regularidad. La manipulación genética, además de ser una cuestión harto discutible bajo múltiples puntos de vista, tiene un futuro incierto y controvertido; y los intentos de creación de lenguas artificiales [principalmente los esfuerzos por lograr una lengua universal: esperanto, interlingua, interglossa, etc.] que, hasta ahora, nunca han logrado una posición importante en el conjunto de lenguas del mundo contemporáneo, tampoco sabemos hacia dónde podrán abocar.

Una posible forma de replantearnos algunas cuestiones como éstas podría consisitr en investigar la hipótesis de Aitchison - cuando intenta, a su vez, refutar la hipótesis del bioprograma de Bickerton- "when languages are faced with a 'spaghetti junction' of possible options, a variety of converging factors often guide them down certain recurrent routes" (Aitchison 1989: 151). Las opciones posibles a menudo dependen en parte de la estructura de la lengua, así como de las elecciones previas, y en parte de los fenómenos sociales, de factores cognitivos generales, de la habilidad computacional y de las limitaciones de la memoria de los usuarios de dicha lengua.

No disponemos de espacio para proponer aquí posibles respuestas a estas y varias otras cuestiones que puedan suscitar los paralelismos biológi- 
cos (en el sentido post-darwiniano). Sin embargo creo que tales paralelismos pueden ser útiles y esclarecedores al aplicarlos al cambio lingüístico y a la evolución de la lengua en general.

Una última cuestión que me parece importante podría ser la noción de ex-aptación. Hasta ahora los teóricos se han concentrado en las adaptaciones, que tienen que ver con rasgos que han evolucionado en un cierto sentido en vistas a desempeñar una función determinada. $Y$ es que las estructuras, por lo general, evolucionan y se desarrollan a fin de desempenar una función determinada; pero pueden igualmente desarrollarse sin finalidad alguna aparente y desempeñar luego un papel completamente distinto al de otras que puedan ser o parecer similares. A estos casos de "reciclaje" evolutivo se les denomina exaptaciones.

Parece que una buena parte de nuestro material genético (o DNA) es "chatarra"; es decir, meros duplicados no-funcionales de genes que sí son funcionales. Y se ha sugerido que este DNA "de deshecho" podría exaptarse, proporcionando un campo abonado para el cambio evolutivo. Los organismos, por consiguiente, deberían considerarse no como máquinas/ estructuras perfectas y predecibles, con un lugar para cada cosa y cada cosa en su lugar, sino más bien como "haces de accidentes históricos", en palabras de R. Lass (1990: 81), citando a Gould. El propio Lass ofrece un caso interesante de exaptación lingüística: el de la terminación -e del adjetivo atributivo que se mantiene vigorosa en Afrikaans [tras haber perdido toda su funcionalidad con la desaparición, hacia 1750 , del sistema desinencial heredado del holandés].

Este y otros conceptos novedosos tomados de la biología pueden abrir alguna perspectiva positiva para el futuro de la lingüística histórica (y de la lingüistica en general). Porque —al igual que G. Sampson (1980: 242) creo que, así como la linguística del pasado reciente ha sido básicamente una lingüística de corte psicológico, de igual modo la lingüística del presente [y del futuro inmediato] es [y tendrá que ser] esencialmente una lingüística biológica.

\section{REFERENCIAS BIBLIOGRÁFICAS}

Aarsleff, H., L.G. Kelly \& H-J.Niederehe (eds.). 1987. Papers in the History of Linguistics. Amsterdam: Benjamins.

Aitchison, J. (1989). "Spaghetti junctions and recurrent routes: some 
preferred pathways in language evolution". En Lingua 77: 151-171. Cambridge Univ. Press.

Anderson, J.M. \& C.Jones, eds. (1974). Historical Linguistics. Vol.I: Syntax, Morphology, Internal and Comparative Reconstruction. Vol.2: Theory and Description in Phonology. Amsterdam: North Holland.

Bailey, C-J.N. \& K. Maroldt (1977). "The French lineage of English". En Meisel (ed.) 1977: 21-53.

Bynon, T.( 1977). Historical Linguistics. Cambridge: Cambridge Univ. Press. Fisiak, J. ed. (1978). Recent Developments in Historical Phonology. The Hague: Mouton.

ed. (1980). Historical Morphology. The Hague: Mouton.

ed. (1984), Historical Syntax. The Hague: Mouton.

Gal, S. (1979). Language Shift. New York: Academic Press.

Gilman, Ch. (1987). "Stolen paradigms: Stammbaum to black box". En Aarsleff, Kelly \& Niederehe (eds.). 1987: 3-11.

Gould, S.J. \& E.S. Vrba (1982). "Exaptation - a missing term in the science of form". En Paleobiology 8: 4-15.

Hindley, R. (1990) The Death of the Irish Language: A Qualified Obituary. London: Routledge.

Hoenigswald, H.M. \& L.F. Wiener, eds. (1987). Biological Metaphor and Cladistic Classification. London: Frances Pinter.

Jespersen, O. (1922). Language: Its Nature, Development and Origin. London: George Allen and Unwin.

Kenstowicz, M. \& C. Kisseberth (1979). Generative Phonology. New York: Academic Press.

Koerner, K., ed. (1983). Linguistics and Evolutionary Theory: Three Essays by August Schleicher, Ernst Haeckel and Wilhelm Bleek. Amsterdan: Benjamins.

Lass, R. (1974). "Linguistic orthogenesis? Scots vowel length and the English length conspiracy". En Anderson \& Jones (eds.). 1974: 311-343

Cambridge Univ. Press.

(1980). On Explaining Language Change. Cambridge: (1990). "How to do things with junk: exaptation in language 
evolution". En Journal of Linguistics 26: 79-102.

McMahon, A.M.S. (1994). Understanding Language Change. Cambridge: Cambridge Univ. Press.

Meisel, J.M., ed. (1977). Langues en contact: pidgins, créoles - languages in contact. Tübingen: TBL Verlag, G. Narr.

Mühlhäusler, P. (1980). "Structural expansion and the process of creolization". En Valdman \& Highfield (eds.) 1980: 19-55

Nerlich, B. (1989). "The evolution of the concept of 'linguistic evolution' in the 19th and 20th century". En Lingua 77: 101-112.

Sampson, G. (1980). Schools of Linguistics: Competition and Evolution. London: Hutchinson.

Stevick, R.D. (1963). "The biological model and historical linguistics". Language 39: 159-169.

Thomason, S.G. \& T. Kaufman. (1991). Language Contact, Creolization, and Genetic Linguistics. Berkeley, Los Angeles \& Oxford: Univ. of California Press.

Todd, L. (1990). Pidgins and Creoles. ( $2^{\circ}$ ed.). London: Routledge.

Traugott, E.C. (1977). "Pidginization, creolization and language change". In Valdman (ed.). 1977: 70-98.

Trudgill, P. ed. (1984). Language in the British Isles. Cambridge: Cambridge Univ. Press.

Valdman, A. (1977). Pidgin and Creole Linguistics. Bloomington: Univ. of Indiana Press.

Studies. New York: Academic Press.

Vincent, N. (1978). “Is sound change teleological?'. En Fisiak, J. (ed.). 1978: 409-429.

Wells, R.S. (1987). "The life and growth of language: metaphors in biology and linguistics". In Hoenigswald \& Wiener (eds.) 1987: 39-80 